A N N A L E S Annales de Bretagne et des Pays de l'Ouest

\title{
Histoire populaire de la Bretagne
}

\section{Erwan Le Gall}

\section{(2) OpenEdition}

\section{Journals}

Édition électronique

URL : https://journals.openedition.org/abpo/5758

DOI : $10.4000 / a b p o .5758$

ISBN : 978-2-7535-8091-6

ISSN : 2108-6443

\section{Éditeur}

Presses universitaires de Rennes

Édition imprimée

Date de publication : 30 juin 2020

Pagination : 207-208

ISBN : 978-2-7535-8090-9

ISSN : 0399-0826

\section{Référence électronique}

Erwan Le Gall, « Histoire populaire de la Bretagne », Annales de Bretagne et des Pays de l'Ouest [En ligne], 127-2 | 2020, mis en ligne le 30 juin 2020, consulté le 05 janvier 2023. URL : http:// journals.openedition.org/abpo/5758; DOI : https://doi.org/10.4000/abpo.5758 
Croix, Alain, Guidet, Thierry, Gullaume, Gwenaël et Guyvarc'H, Didier, Histoire populaire de la Bretagne, Rennes, PUR, 2019, 496 p.

Il est toujours étrange de vouloir entreprendre l'histoire de quelque chose qui n'existe pas et les quatre auteurs de cette Histoire populaire de la Bretagne en sont pleinement conscients : dès les prémices de leur ouvrage, s'inscrivant dans le sillage des " communautés imaginées " du politologue américain B. Anderson, ils affirment que " le peuple n'existe pas, qu'il est composite, mouvant, porteur de voix diverses ". Pourtant, c'est bien dans une " histoire populaire de la Bretagne " qu'Alain Croix, Thierry Guidet, Gwenaël Guillaume et Didier Guyvarc'h se sont lancés, prolongeant d'une certaine manière une démarche entreprise à l'échelle nantaise en 2017. Disons-le de suite, le résultat est particulièrement intéressant. La connaissance quasi encyclopédique des auteurs alliée à un style d'une grande clarté confère une évidente portée pédagogique au propos. En d'autres termes, nous sommes en présence d'un livre des plus accessibles, y compris sur le plan financier. C'est là un point qu'il faut souligner tant il trahit un engagement fort, et éminemment louable, des auteurs et de leur éditeur.

Cette réussite est à souligner car l'histoire " populaire " n'est pas sans risques. Initiée par H. Zinn et mise au goût du jour en France par des auteurs aussi référencés que G. Noiriel ou M. Zancarini-Fournel, cette écriture entend prendre le relais de l'histoire sociale - sans doute trop aride et riche en chiffres pour le grand public - et attaquer de front un récit qui, quand il n'est pas national, n'envisage le réel que par les élites. Là encore, l'intention est éminemment louable mais n'est pas sans poser un certain nombre de questions. En effet, ne s'agit-il pas là d'un simple effet de mode, à la manière de la " contre-histoire ", un temps en vogue? De même, peut-on sérieusement écrire l'Histoire que d'un seul point de vue? La discipline n'est-elle pas fondamentalement affaire de variations de focales et d'échelles? En d'autres termes, n'est-ce pas là renouveler les erreurs de cette histoire du travail qui ne se basait que sur le mouvement social pour ignorer les patrons, ou de cette histoire militaire qui, après n'avoir eu d'yeux que pour les généraux - les " grands hommes " - n'en a eu que pour les soldats de $2^{\mathrm{e}}$ classe, poussant en certains cas le vice jusqu'à considérer un simple sous-lieutenant comme faisant partie du " commandement "? Les auteurs connaissent ces travers et ne sont pas dupes quant à l'exercice de style auquel ils se livrent. Eux-mêmes confessent d'ailleurs bien volontiers qu'il est malaisé de définir ce qui relève ou non du peuple : "si frontière il y a, elle est à penser comme une zone, pas comme une ligne " plaident-ils. En d'autres termes, puisque le social ne saurait se résumer à la distinction binaire entre dominants et dominés, quid des catégories intermédiaires (telles qu'étudiées par exemple par Jean Le Bihan) ou des classes dites "moyennes "? Sans doute que cette question ne se pose véritablement qu'avec le $\mathrm{xx}^{\mathrm{e}}$ siècle. Toujours est-il qu'il y a là une question qui, nous semble-t-il, aurait gagné à être plus prise en compte.

Appliqué à l'espace particulier qu'est la péninsule armoricaine, l'histoire populaire courrait également un autre risque, pire encore sans doute que le premier : celui d'une fresque essentialiste, tissant au fil de la continuité chronologique la trame d'une destinée, celle du " peuple breton ". Là encore, naviguant entre Charybde et Scylla, les auteurs prennent bien soin de ne pas tomber dans ce piège en dénonçant, dès les premières pages du volume, ces quelques "milieux intellectuels bretons " qui, "dès la fin du XVIII ${ }^{\mathrm{e}}$ siècle et tout au long des XIX et XX ${ }^{\mathrm{e}}$ siècles ", sont "saisis d'une obsession celtomane parant ce peuple de toutes les vertus ". Pour autant, malgré toutes ces précautions, il y a tout lieu de se demander si la trame résolument chronologique et parfaitement linéaire de l'ouvrage ne contribue pas, malgré-tout, à instiller dans l'esprit des lecteurs les moins armés sur le plan histo- 
riographique l'idée d'une Bretagne qui serait " éternelle ". Là est, nous semble-t-il, une question d'importance tant ce volume est, à l'évidence, destiné à un lectorat pas nécessairement conscient de ces enjeux.

Et c'est sans doute là qu'on en revient à la question initiale, à savoir la véritable nature de cette écriture qu'est l'histoire " populaire ». En tant que genre, relève-telle réellement de cette discipline qu'est l'histoire ou, au contraire, d'autres desseins parfaitement honorables et que l'on avait coutume de qualifier, jadis, d'éducation " populaire "? Car il ne faut pas s'y tromper. L'un des grands mérites de ce riche volume est de mettre en perspective des réalités historiques dont la portée civique est d'autant plus essentielle qu'elles heurtent de plein fouet le régime des mémoires. Ainsi, quand à propos de la traite les auteurs rappellent que sur un navire négrier " le taux de mortalité de l'équipage au cours d'une expédition est supérieur à celui des captifs " car " un esclave est une denrée plus précieuse qu'un simple matelot " (p. 24), que celui-ci soit du reste breton ou non. Là n'est pas entrer dans une surenchère victimaire mais bien rappeler des faits, objectifs et intangibles.

Certes, l'ouvrage n'évite pas quelques maladresses. Si l'on suit volontiers les auteurs lorsqu'ils rappellent que le sentiment régional est indissociable du contact avec l'Autre, nous sommes en revanche beaucoup plus circonspect lorsqu'ils affirment qu'on " est breton que vu par des étrangers qui reconnaissent une langue incomprise ". N'est-ce pas en effet réduire la Bretagne à la partie occidentale de la frontière linguistique? De la même manière, avouons notre perplexité en lisant que la " plupart " des poilus bretons "sont issus d'un monde marqué par la pauvreté et l'analphabétisme " (p. 349) : le succès rencontré par la Grande Collecte à l'occasion du centenaire de la Grande Guerre invitait à notre humble avis à un tableau plus nuancé.

Mais il n'en demeure pas moins que les auteurs savent aller à l'encontre des idées reçues. Ainsi lorsqu'ils rappellent que si le fouage double sous Anne de Bretagne, après avoir déjà quadruplé sous son père François II, c'est " pour financer la politique d'opposition à la monarchie ". De même, à propos de la bataille de Saint-Aubin-du-Cormier quand, à rebours du roman national forgé au XIX siècle, ils rappellent que le futur roi de France Louis XII combat bel et bien dans le " camp breton ". Et peu importe au final que l'on adhère ou non à cet exercice de style qu'est l'histoire " populaire ". Les auteurs ont fait œuvre utile et là est bien ce qui, au final, compte. 